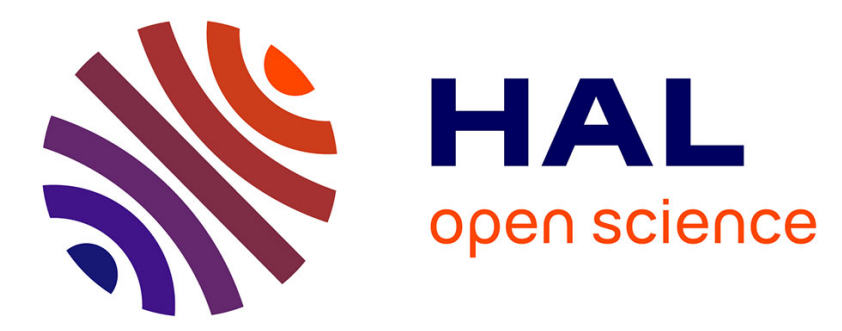

\title{
Indirect Four-Electron Oxygen Reduction Reaction on Carbon Materials Catalysts in Acidic Solutions
}

Guo-Liang Chai, Mauro Boero, Zhufeng Hou, Kiyoyuki Terakura, Wendan Cheng

\section{- To cite this version:}

Guo-Liang Chai, Mauro Boero, Zhufeng Hou, Kiyoyuki Terakura, Wendan Cheng. Indirect FourElectron Oxygen Reduction Reaction on Carbon Materials Catalysts in Acidic Solutions. ACS Catalysis, 2017, 7 (11), pp.7908-7916. 10.1021/acscatal.7b02548 . hal-02991540

\author{
HAL Id: hal-02991540 \\ https://hal.science/hal-02991540
}

Submitted on 22 Dec 2020

HAL is a multi-disciplinary open access archive for the deposit and dissemination of scientific research documents, whether they are published or not. The documents may come from teaching and research institutions in France or abroad, or from public or private research centers.
L'archive ouverte pluridisciplinaire HAL, est destinée au dépôt et à la diffusion de documents scientifiques de niveau recherche, publiés ou non, émanant des établissements d'enseignement et de recherche français ou étrangers, des laboratoires publics ou privés. 


\section{Indirect Four-Electron Oxygen Reduction Reaction}

\section{on Carbon Materials Catalysts in Acidic Solutions}

Guo-Liang Chai ${ }^{*}, 1$, Mauro Boero ${ }^{2}$,Zhufeng Hou ${ }^{3}$, Kiyoyuki Terakura ${ }^{3,4}$, and Wendan Cheng ${ }^{l}$

${ }^{1}$ State Key Laboratory of Structural Chemistry, Fujian Institute of Research on the Structure of Matter, Chinese Academy of Sciences (CAS), Fuzhou, 350002 Fujian, People's Republic of China.

${ }^{2}$ University of Strasbourg, Institut de Physique et Chimie des Matériaux de Strasbourg (IPCMS), CNRS UMR 7504, 23 rue du Loess, F-67034 Strasbourg, France.

${ }^{3}$ National Institute for Materials Science (NIMS), 1-2-1 Sengen, Tsukuba, Ibaraki 305-0047, Japan.

${ }^{4}$ Japan Advanced Institute of Science and Technology (JAIST), 1-1 Asahidai, Nomi, Ishikawa 923-1292, Japan

ABSTRACT: Developing cost-effective and high performance oxygen reduction reaction (ORR) catalysts is a fundamental issue in fuel cells and metal-air batteries. To this aim, carbon materials catalysts (CMCs) are extensively investigated because of their performance comparable to noble metal based catalysts in alkaline solution. Yet, acidic solutions are desirable for an efficient proton-exchange across Nafion membranes to yield high power density for commercial 
applications. However, the ORR performance of CMCs in acidic solutions is rather low because of undesirable two-electron processes and $\mathrm{OH}$ radical formation. By using first principles simulations, in this work we elucidate the mechanisms and identify the active sites of $2 \mathrm{e}^{-}$ORR processes for indirect $4 \mathrm{e}^{-} \mathrm{ORR}$. We provide evidence for the fact that nitrogen doped StoneWales defects in graphene favor an indirect four-electron ORR upon $\mathrm{H}_{2} \mathrm{O}_{2}$ formation and reduction. The low ORR potential for metal free CMCs is ascribed to $\mathrm{H}_{2} \mathrm{O}_{2}$ formation via hydrogen abstraction and the critical point for $\mathrm{OH}$ radical generation on transition metal based CMCs is $0.82 \mathrm{~V}$. Moreover, we provide an insight into the indirect $4 \mathrm{e}^{-} \mathrm{ORR}$ which serves as a guide for suppressing undesired $2 \mathrm{e}^{-} \mathrm{ORR}$, avoiding $\mathrm{OH}$ production, and promoting direct four electron ORR on CMCs. These results disclose a new strategy for developing high efficient ORR on CMCs in acidic solutions.

KEYWORDS: Oxygen reduction reaction; Fuel cells; Carbon materials catalysts; Acidic Solutions; First principles simulations, Metadynamics.

\section{INTRODUCTION}

Electrochemical oxygen reduction reaction (ORR) is the common process occurring at the cathode of fuel cells and metal-air batteries. Such a reaction is kinetically rather slow and, as such, is responsible for the degree of efficiency of electrochemical devices for clean energy applications. ${ }^{1-6}$ To date, an economically affordable cathode ORR catalysts represents still a stumbling block because of the high cost of the routinely used noble metals. ${ }^{7}$ More recently, carbon materials catalysts (CMCs) have been pioneered as an economically appealing alternative for the expensive Pt based catalysts. ${ }^{8-9}$ In these systems, the specific framework of the CMCs may be graphene, carbon nanotubes, fullerenes, or amorphous carbons, depending on the 
preparation, synthesis procedure and experimental conditions. Moreover, an appreciable enhancement of the catalytic activity of these carbon-based structures is obtained by doping with $\mathrm{B}, \mathrm{N}, \mathrm{P}, \mathrm{S}$ and other heteroatoms. ${ }^{10}$ To reach the stage of practical application, it is crucial to develop ORR catalysts able to operate in acidic solution, since proton transfer processes across Nafion membranes are much faster in acidic electrolytes than in alkaline ones and a fast proton transfer is crucial to generate a higher power density. Although the ORR performance of some metal free CMCs have already been shown to be comparable to the widely used Pt catalysts in alkaline solution, their performance in acidic solution is still far below the one of Pt because of the occurrence of 2e- ORR to from $\mathrm{H}_{2} \mathrm{O}_{2} \cdot{ }^{8,10-13}$ Transition metal (TM) based CMCs, such as the worldwide studied $\mathrm{FeN}_{\mathrm{x}}$ systems, are favorable to ORR in acidic solution. Their drawback is the fact that these systems realize Fenton's reactions, reducing $\mathrm{H}_{2} \mathrm{O}_{2}$ to $\mathrm{OH}$ radicals and destroying the catalysts. ${ }^{14}$

The issues briefly summarized here for ORR in acidic solutions are mainly related to an indirect four electron ORR process that can be seen as composed of distinct two electron ORR processes. ${ }^{15}$ However, to date, no study clarified the mechanisms for this indirect four electron ORR process operated by CMCs in acidic solution. Yet, this is a serious issue that hinders the commercial application of CMCs to replace Pt catalysts in fuel cells. Hence, understanding the underlying mechanisms of such an indirect four-electron ORR in acidic solution is of primary importance for the development of efficient CMCs.

In most of the experimental studies reported so far, the discrimination between two-electron and four-electron ORR is done on the basis of the electron transfer number (ETN) deduced from the percentage of produced $\mathrm{H}_{2} \mathrm{O}_{2}$. However, this empirical method is ambiguous and unable to distinguish direct and indirect four-electron ORR processes. For instance, if hydrogen peroxide 
$\mathrm{H}_{2} \mathrm{O}_{2}$ is first formed via a two-electron $\mathrm{ORR}$ and then the $\mathrm{H}_{2} \mathrm{O}_{2}$ is further reduced by a subsequent two-electron ORR to water, the ETN of this indirect ORR pathway turns out to be equal to four, thus identical to a full four-electron process. A recent investigation of the ORR processes on CMCs rationalized in terms of Damjanovic and Wroblowa models claimed that both two-electron process, direct and indirect four-electron pathways, can occur in CMCs, while the corresponding mechanisms and the active sites are still a matter of debate. ${ }^{15}$

Here we make use of first principles simulations to unravel the indirect four-electron ORR process in CMCs consisting in (i) a two-electron $\mathrm{H}_{2} \mathrm{O}_{2}$ formation and (ii) a two-electron $\mathrm{H}_{2} \mathrm{O}_{2}$ reduction in acidic solution. The catalytic models considered are nitrogen doped metal-free and Fe based CMCs. Our results indicate that $\mathrm{H}_{2} \mathrm{O}_{2}$ can form via a hydrogen abstraction mechanism on CMCs surfaces. We also find that at least three ORR mechanisms are possible for $\mathrm{H}_{2} \mathrm{O}_{2}$ reduction via the generation of a hydroxyl anion $\mathrm{OH}^{-}$, an $\mathrm{OH}$ radical or an $\mathrm{H}_{2} \mathrm{O}$ molecule, respectively. The $\mathrm{N}$ doped Stone-Wales defect can promote the formation of $\mathrm{H}_{2} \mathrm{O}_{2}$ via hydrogen abstraction and favor the $\mathrm{H}_{2} \mathrm{O}_{2}$ reduction via the mechanisms mentioned above. This facilitates a combined indirect four-electron ORR process. Our findings suggest also that the hydrogen abstraction mechanism can lower the electro-chemical potential to $\sim 0.4 \mathrm{~V}$ and hence lower the efficiency of ORR. ${ }^{16}$ Instead, the $\mathrm{OH}$ radical generation during the $\mathrm{H}_{2} \mathrm{O}_{2}$ reduction would decrease the durability of the catalyst with a critical half-wave potential of $0.82 \mathrm{~V}$. Thus, the

development of high performance CMCs in acidic environments requires methods and techniques suited to overcome these negative issues.

\section{SIMULATION METHODS}


Nitrogen doped non-defective graphene and an analogous system including a Stone-Wales defect were considered, on the basis of all our former works, as model templates for CMCs (see Figure 1). Simulations were performed with the Car-Parrinello molecular dynamics (CPMD) method within the density functional theory (DFT) framework. ${ }^{17-19}$ This approach is sufficient to investigate processes occurring on a picosecond time scale for which activation barriers of a few $k_{B T}$ are involved. This is for instance the case of the activation of an $\mathrm{O}_{2}$ molecule by hydrogen abstraction. The simulation cell of each system is orthorhombic and contains about 200 atoms as specified elsewhere. ${ }^{9}$ Lattice parameters for each structure considered are reported in the supporting information. As an example, the cell lattice parameters for the G-N structure are $\mathrm{a}=12.28, \mathrm{~b}=12.76, \mathrm{c}=15.00$ and $\alpha=\beta=\gamma=90^{\circ}$. CPMD simulations were complemented by the Blue Moon ensemble (BME) free energy sampling technique in a canonical NVT ensemble at $300 \mathrm{~K}$ whenever the free energy barriers involved are too large to be overcome by standard CPMD and a single reaction coordinate is sufficient to describe the activated process. The CPMD equations of motion are numerically integrated with a time step of 4.0 a.u. ${ }^{20}$ to ensure a good control of the constants of motion. The exchange-correlation functional was described by a gradient-corrected spin-unrestricted Hamprecht-Cohen-Tozer-Handy (GGA-HCTH) formulation. ${ }^{21}$ The corevalence interaction was described by norm-conserving Troullier-Martins pseudopotentials (PP) for $\mathrm{C}, \mathrm{N}, \mathrm{O}$ and $\mathrm{P},{ }^{22}$ while an analytical von Barth-Car one was used for $\mathrm{H} \cdot{ }^{23}$ The sampling of the Brillouin zone was restricted to the $\Gamma$ point. The spin state of the various systems considered here are identical to the ones treated in our former work. ${ }^{9}$

Whenever a single reaction coordinate is insufficient, as (e.g.) for the $\mathrm{H}_{2} \mathrm{O}_{2}$ dissociation on CMCs, we resorted to the metadynamics approach ${ }^{24,25}$ to inspect reaction pathways and to sort out free energy barriers. More precisely, we adopted the variational formulation of the 
metadynamics $^{26}$ in which collective variables (CVs) $s_{\alpha}$ become dynamical degrees of freedom in the Lagrangean:

$$
L=L^{C P}\left[\mathrm{R},\left\{\psi_{i}\right\}\right]+\sum_{\alpha} \frac{1}{2} M_{\alpha} \dot{S}_{\alpha}^{2}-\sum_{\alpha} \frac{1}{2} k_{\alpha}\left[S_{\alpha}(R)-S_{\alpha}\right]^{2}-V(t, s)
$$

being $L^{C P}\left[\mathrm{R},\left\{\Psi_{i}\right\}\right]$ is the standard Car-Parrinello Lagrangian. ${ }^{17}$ The second and third terms in the right hand side of Eq. (1) are the fictitious kinetic energy and the restraining potential, forcing the instantaneous $\mathrm{CV} s_{\alpha}(t)$ to fluctuate around its corresponding mathematical expression $s_{\alpha}(\boldsymbol{R})$. The time-evolving term $V(t, s)$ is the history-dependent potential where penalty functions accumulate along the metadynamics trajectory. This allows to fill progressively the free-energy minima and to force the reactions to occur on an affordable time scale. The explicit form of the potential used in this work is a superposition of small Gaussian penalty functions:

$$
V(t, s)=\sum_{t_{i}<t}\left[W_{i} \exp \left\{-\frac{\left(s-s^{i}\right)^{2}}{2\left(\Delta s^{\perp}\right)^{2}}\right\} \exp \left\{-\frac{\left(\left(s^{i+1}-s^{i}\right) \cdot\left(s-s^{i}\right)\right)^{2}}{2\left(\Delta s_{i}^{\|}\right)^{4}}\right\}\right]
$$

where $t$ is the actual simulation time, $i$ is the index representing the metadynamics steps, and $\Delta \mathrm{s}_{i}^{\|}=\left|\mathrm{s}^{i+1}-\mathrm{s}^{i}\right|$. The first exponential gives the hill's shape in the direction perpendicular to the trajectory, whereas the second exponential tunes the shape along the trajectory. The Gaussian height $W_{i}$ and the width $\Delta \mathrm{s}^{\perp}$ are selected by the user and determine the accuracy in the free energy resolution and in the collective variable sampling, respectively. For our purposes, these values are set to $0.016 \mathrm{eV}$ and 0.1 (in units of collective variables), respectively. In each metadynamics run, a new Gaussian contribution was added to $V(s, t)$ every 150 steps. In our metadynamics simulations, two collective variables were employed, namely the coordination number between the two $\mathrm{O}$ atoms in $\mathrm{H}_{2} \mathrm{O}_{2}(\mathrm{CV} 1)$ and the distance between one $\mathrm{O}$ atom in $\mathrm{H}_{2} \mathrm{O}_{2}$ 
and the approaching $\mathrm{C}$ site on the CMCs surfaces (CV2). The coordination number (CN) is analytically described as:

$$
N_{\text {coord }}(A, B)=\sum_{i=1}^{N_{A}} \frac{1}{N_{A}}\left[\sum_{i=1}^{N_{B}} \frac{1-\left(r_{i j} / d_{A B}\right)^{p}}{1-\left(r_{i j} / d_{A B}\right)^{(p+q)}}\right]
$$

The integer exponents $p$ and $q$ are set to 8 . For CV1, the fictitious mass of the kinetic term was tuned to $M_{\alpha}=60.0$ a.u., and the harmonic coupling constants were set to $k_{\alpha}=1.0$ a.u.. For CV2, the fictitious mass for the kinetic term is set to $M_{\alpha}=15.0$ a.u., and the harmonic coupling constants were set to $k_{\alpha}=0.25$ a.u.. We remark that the mathematical function (3) of the $\mathrm{CN}$ is positive defined. Yet, we make use of the variational formulation of the metadynamics approach. According to this formulation, the collective variables $\mathrm{CV}(t)$ evolve with their own EulerLagrange equations of motion. ${ }^{26}$ This motion is constrained by a bounding harmonic potential $k\left(\mathrm{CV}(t)-N_{\text {coord }}(A, B)\right)^{2}$ along the (meta)dynamical evolution and for this reason $\mathrm{CV}(t)$ oscillates around the (never negative) $N_{\text {coord }}(A, B)$, but occasionally, when $N_{\text {coord }}(A, B)=0$, can assume instantaneously slightly negative values which can appear in the reconstructed free energy plot.

Free energy variations for each elementary step were computed by auxiliary DFT calculations done with the Quantum ESPRESSO package. ${ }^{27}$ The adsorption energies of ORR intermediates are calculated by using $\mathrm{H}_{2} \mathrm{O}(l)$ and $\mathrm{H}_{2}(g)$ as references. Details for calculating limiting potentials are provided in the Supporting Information. The generalized gradient approximation of PerdewBurke-Ernzerhof (GGA-PBE) was used for the exchange correlation functional ${ }^{28}$ thus providing also a benchmark for different GGA (PBE and HCTH) prescriptions. Spin unrestricted calculations were done in all cases. The kinetic energy cutoffs for the wavefunction, expanded in a plane-wave basis set, and the charge density were set to 35 Ry and 350 Ry, respectively. 


\section{RESULTS AND DISCUSSION}

\subsection{Active sites and mechanisms for $\mathrm{H}_{2} \mathrm{O}_{2}$ formation on CMCs.}

Chemical reactions are driven by both thermodynamics and kinetics. In the present study, we provide an insight into both thermodynamics and kinetics for the indirect four-electron ORR. This indirect four-electron ORR consists of a two-electron ORR responsible for the formation of $\mathrm{H}_{2} \mathrm{O}_{2}$ and a subsequent two-electron ORR for the conversion of $\mathrm{H}_{2} \mathrm{O}_{2}$ into water. The ORR at the cathode is a three-phase reaction, which was thought to be activated by $\mathrm{O}_{2}$ adsorption onto the exposed surface of noble metals ( $\mathrm{Pt}, \mathrm{Pd}-\mathrm{Hg}$ and $\mathrm{Ag}-\mathrm{Hg}){ }^{29,30}$ This is indeed the case in $\mathrm{Pt}$ nanoclusters. ${ }^{31}$ Yet, our recent investigation indicated that the barrier for $\mathrm{O}_{2}$ activation by abstraction of a hydrogen site on metal free CMCs can be lower than that for $\mathrm{O}_{2}$ adsorption at least on surfaces. This, in turn, can result in a new mechanisms for $\mathrm{H}_{2} \mathrm{O}_{2}$ formation on

CMCs. ${ }^{16,32}$ As the $\mathrm{O}_{2}$ adsorption mechanism has been extensively studied, here we focus on the possible $\mathrm{H}$ abstraction mechanism and on the active sites at the surface of CMCs systems which are prone to form $\mathrm{H}_{2} \mathrm{O}_{2}$.

The CMCs systems used in our simulations are the $\mathrm{N}$ doped and Fe based CMCs shown in Figures 1 and S1, respectively. The G-N and G-NN ${ }^{\mathrm{AB}}$ structures indicate the presence of either one or two graphitic $\mathrm{N}$ sites replacing $\mathrm{C}$ in the perfect graphene network. The choice of these two specific sites has been done on the basis of our former works. ${ }^{33,34}$ The SW-N1, SW-N2, SW-N3 and SW-N3N3' structures indicate, instead, different possible $\mathrm{N}$ doping sites in graphene sheets containing Stone-Wales defects. The elementary steps of the H abstraction mechanism for twoelectron $\mathrm{H}_{2} \mathrm{O}_{2}$ formation are the following three: ${ }^{16}$ 


$$
\begin{aligned}
& *+\left(\mathrm{H}_{(a q)}^{+}+e^{-}\right) \rightarrow * \mathrm{H} \\
& * \mathrm{H}+e^{-}+\mathrm{O}_{2(g)} \rightarrow *+\mathrm{OOH}_{(a q)}^{-} \\
& *+\mathrm{OOH}_{(a q)}^{-}+\mathrm{H}_{(a q)}^{+} \rightarrow *+\mathrm{H}_{2} \mathrm{O}_{2(a q)}
\end{aligned}
$$

where the symbol * indicates a possible active site on the CMCs surface. For the H abstraction, the first step, involving an electron transfer, is the hydrogenation of the CMCs surface. Then, the second step, also involving an electron transfer process, is the formation of an $\mathrm{OOH}^{-}$ intermediate. ${ }^{9,16}$ Finally, the $\mathrm{OOH}^{-}$intermediate is expected to react with $\mathrm{H}^{+}$to form a $\mathrm{H}_{2} \mathrm{O}_{2}$. The reaction free energy for the overall $\mathrm{H}_{2} \mathrm{O}_{2}$ formation is $-1.40 \mathrm{eV}$. The free energy variation of the first step is the hydrogenation energy $\Delta \mathrm{G} * \mathrm{H}$. The reaction energy of the third step is a constant having an experimental value of $-0.69 \mathrm{eV}$ under standard conditions. ${ }^{35,36}$ Hence, the reaction free energy of the second step can be obtained by subtracting the free energy variations of the other two steps from the total reaction energy, specifically, $-0.71-\Delta \mathrm{G} * \mathrm{H}$. Thus, the limiting potential, due to the rate determining step for the formation of $\mathrm{H}_{2} \mathrm{O}_{2}$ via $\mathrm{H}$ abstraction, can be expressed as: ${ }^{16}$

$$
U_{L}=\operatorname{Min}\left\{-\Delta G_{*_{H}}, 0.71+\Delta G_{*_{H}}\right\}
$$

Here, $U_{L}$ is determined by the limiting step, corresponding to the lowest energy decrease. The limiting potential becomes then the highest potential below which all the free energies variations for each electrochemical steps are downhill, although not necessarily barrierless. This can be compared directly with the experimental half-wave potential. The free energy variation for each elementary step in the $\mathrm{H}_{2} \mathrm{O}_{2}$ formation and reduction processes can be obtained from the related total energies as described in the Supporting Information. Details about this mechanism have been reported by our previous study. ${ }^{16}$ Here we focus specifically on the screening of the active 
sites at the surface of $\mathrm{CMCs}$ for $\mathrm{H}_{2} \mathrm{O}_{2}$ formation. More importantly, we pay special attention to the indirect four electron ORR by combining the $\mathrm{H}_{2} \mathrm{O}_{2}$ formation and reduction processes. Following this roadmap, we started by computing the hydrogenation energies of the different sites on the structures shown in Figure 1. The results are summarized in Figure 2(a). Namely, simulations show that the hydrogenation step is endothermic for the G-N, G-NNAB, and SWN3N3' structures; this, in turn, suggests that the H abstraction mechanism is unlikely to occur for these structures. The hydrogenation energies calculated for the SW-N1, SW-N2, and SW-N3 structures turn out to be $-0.44 \mathrm{eV},-0.25 \mathrm{eV}$, and $-0.34 \mathrm{eV}$ for the most favorable sites, respectively. This implies that on these sites the $\mathrm{H}$ abstraction mechanism is thermodynamically possible.

To make this point clearer, in Figure 3 we report the scatter-plot data for $\mathrm{H}$ abstraction under standard conditions in terms of the so-called volcano plot. In any type of fuel cells and rechargeable batteries, a quantity of major interest is the limiting potential, mainly referred to charge and discharge stages. ${ }^{37}$ As shown in the volcano plot of Figure 3, the limiting potentials for the SW-N1, SW-N2, and SW-N3 systems are $0.27 \mathrm{~V}, 0.25 \mathrm{~V}$, and $0.34 \mathrm{~V}$, respectively. We find that the maximum limiting potential for $\mathrm{H}$ abstraction mechanism is about $0.4 \mathrm{~V}$, and the SW-N1, SW-N2, and SW-N3 systems are thermodynamically possible for $\mathrm{H}_{2} \mathrm{O}_{2}$ formation via the $\mathrm{H}$ abstraction mechanism. We remark that the computed limiting potential is clearly lower than the standard potential $(0.70 \mathrm{~V})$ for $\mathrm{H}_{2} \mathrm{O}_{2}$ formation due to the $\mathrm{H}$ abstraction process. This agrees with the experimental observations indicating that the ORR half-wave potential of metal free CMCs in acidic solution is less than $0.4 \mathrm{~V} .^{38-40}$

As the $\mathrm{O}_{2}$ adsorption mechanism and $\mathrm{H}$ abstraction mechanism are kinetically competing processes, we proceeded to compute the $\mathrm{H}$ abstraction kinetic profiles for the three structures 
indicated above (SW-N1, SW-N2, and SW-N3), sketched in Figure 4. The H abstraction barrier for the SW-N3 structure is $0.52 \mathrm{eV}$, while the corresponding ones for the SW-N1 and SW-N2 structures are higher than $0.6 \mathrm{eV}$. We also checked the barrier for proton transfer from the solution to the catalytic surface of the SW-N3 system. These results are shown in Figure S2 of the Supporting Information. Such a barrier is lower than the corresponding one for $\mathrm{H}$ abstraction, as expected, and amounts to about $0.26 \mathrm{eV}$. Since the $\mathrm{O}_{2}$ adsorption and the $\mathrm{H}$ abstraction are competing processes, the $\mathrm{H}$ abstraction mechanism might occur provided that the related activation barrier is lower than $0.6 \mathrm{eV}$, as discussed above. As shown in Figure 4, the $\mathrm{O}_{2}$ adsorption barriers are larger than the $\mathrm{H}$ abstraction ones in all cases. Given the scenario depicted so far, only the SW-N3 system appears to be both thermodynamically and kinetically favorable for $\mathrm{H}_{2} \mathrm{O}_{2}$ formation via $\mathrm{H}$ abstraction.

\subsection{Active sites and mechanisms for $\mathrm{H}_{2} \mathrm{O}_{2}$ reduction on CMCs.}

The mechanisms for subsequent two-electron ORR responsible for the conversion of $\mathrm{H}_{2} \mathrm{O}_{2}$ into water has been rarely studied and is still unclear to a great extent. As a consequence, the overall indirect four-electron mechanism remains to be elucidated. For the subsequent reduction of $\mathrm{H}_{2} \mathrm{O}_{2}$ to a water molecule, at least three alternative mechanisms are possible. These have been explored according to the results of metadynamics simulations discussed below i.e. the $\mathrm{H}_{2} \mathrm{O}_{2}$ molecule can be decomposed into $(* \mathrm{OH}+\mathrm{OH})$ or $\left({ }^{*} \mathrm{O}+\mathrm{H}_{2} \mathrm{O}\right)$ at the first step depend on the specific catalytic surface. The produced $\mathrm{OH}$ group in solution can be $\mathrm{OH}^{-}$ion or $\mathrm{OH}$ radical, which leads to two different mechanisms. We name them $\mathrm{OH}^{-}$ion and $\mathrm{OH}$ radical mechanisms, respectively. The third one is named $\mathrm{H}_{2} \mathrm{O}$ mechanism as $\mathrm{H}_{2} \mathrm{O}$ is produced in the first step. These alternative reaction mechanisms are sketched in Figure 5. The first one, termed $\mathrm{OH}^{-}$ion mechanism hereafter, is composed of the following elementary steps: 


$$
\begin{aligned}
& *+\mathrm{H}_{2} \mathrm{O}_{2(a q)}+2\left(\mathrm{H}_{(a q)}^{+}+e^{-}\right) \rightarrow * \mathrm{OH}+\mathrm{OH}_{(a q)}^{-}+2 \mathrm{H}_{(a q)}^{+}+e^{-} \\
& * \mathrm{OH}+\mathrm{OH}_{(a q)}^{-}+2 \mathrm{H}_{(a q)}^{+}+e^{-} \rightarrow * \mathrm{OH}+\mathrm{H}_{2} \mathrm{O}_{(a q)}+\mathrm{H}_{(a q)}^{+}+e^{-} \\
& * \mathrm{OH}+\mathrm{H}_{2} \mathrm{O}_{(a q)}+\mathrm{H}_{(a q)}^{+}+e^{-} \rightarrow^{*}+2 \mathrm{H}_{2} \mathrm{O}_{(a q)}
\end{aligned}
$$

According to this reaction pathway, in the first elementary step the $\mathrm{H}_{2} \mathrm{O}_{2}$ hydrogen peroxide dissociates into an ${ }^{*} \mathrm{OH}$ intermediate anchored to the $\mathrm{CMC}$ surface and an $\mathrm{OH}^{-}$hydroxyl anion. Then the $\mathrm{OH}^{-}$hydroxyl anion reacts with $\mathrm{H}^{+}$in solution and this step is exoenergetic, being characterized by an energy gain of $-0.83 \mathrm{eV}$ in standard condition. ${ }^{35,36}$ We remark that this step does not involve any electron transfer process. The final step consists in the removal of the $* \mathrm{OH}$ intermediate adduct via an electron transfer process characterized by a free energy variation indicated as $-\Delta \mathrm{G} * \mathrm{OH}$ in the figure. The standard potential for $\mathrm{H}_{2} \mathrm{O}_{2}$ reduction to water is $1.77 \mathrm{~V}$. Thus, the overall free energy variation of the first step is given by $-3.54+0.83+\Delta \mathrm{G} * \mathrm{OH}$. The maximum limiting potential for this specific reaction pathway is then $1.36 \mathrm{~V}$, corresponding to $\Delta \mathrm{G} * \mathrm{OH}=1.36 \mathrm{eV}$.

The second reaction mechanism, $\mathrm{OH}$ radical mechanism, is shown in Figure 5. The elementary steps are as follows:

$$
\begin{aligned}
& *+\mathrm{H}_{2} \mathrm{O}_{2(a q)}+2\left(\mathrm{H}_{(a q)}^{+}+e^{-}\right) \rightarrow * \mathrm{OH}+\mathrm{OH}_{(a q)}+2\left(\mathrm{H}_{(a q)}^{+}+e^{-}\right) \quad(11) \\
& * \mathrm{OH}+\mathrm{OH}_{(a q)}+2\left(\mathrm{H}_{(a q)}^{+}+e^{-}\right) \rightarrow *+\mathrm{OH}_{(a q)}+\mathrm{H}_{2} \mathrm{O}_{(a q)}+\mathrm{H}_{(a q)}^{+}+e^{-} \\
& *+\mathrm{OH}+\mathrm{H}_{2} \mathrm{O}_{(a q)}+\mathrm{H}_{(a q)}^{+}+e^{-} \rightarrow * \mathrm{OH}+\mathrm{H}_{2} \mathrm{O}_{(a q)}+\mathrm{H}_{(a q)}^{+}+e^{-} \\
& * \mathrm{OH}+\mathrm{H}_{2} \mathrm{O}_{(a q)}+\mathrm{H}_{(a q)}^{+}+e^{-} \rightarrow *+2 \mathrm{H}_{2} \mathrm{O}_{(a q)}
\end{aligned}
$$

In this pathway, the first step also generates an $* \mathrm{OH}$ bound to the catalytic surface. However, here the $\mathrm{OH}$ group released in solution is a radical instead of a hydroxyl anion, which makes this a non-electron transfer step. The second step is the removal of the $* \mathrm{OH}$ intermediate from the 
$\mathrm{CMC}$ surface, which is accompanied by a free energy variation $-\Delta \mathrm{G} * \mathrm{OH}$. Assuming that the $\mathrm{OH}$ group binds to the same catalytic site, the third step would be the formation of another $* \mathrm{OH}$, whereas the fourth step is again represented by the removal of the ${ }^{*} \mathrm{OH}$ intermediate. The related free energy variations for the third and fourth steps are $-2.72+\Delta \mathrm{G} * \mathrm{OH}$ and $-\Delta \mathrm{G} * \mathrm{OH}$, respectively. In this case, the maximum limiting potential is $0.82 \mathrm{~V}$, which allows to infer that $\Delta \mathrm{G}{ }^{*} \mathrm{OH}=0.82 \mathrm{eV}$.

The third reaction pathway is the $\mathrm{H}_{2} \mathrm{O}$ mechanisms, involving the generation of an $\mathrm{H}_{2} \mathrm{O}$ molecule and the binding of an *O intermediate to the surface of the system.

$$
\begin{aligned}
& *+\mathrm{H}_{2} \mathrm{O}_{2(a q)}+2\left(\mathrm{H}_{(a q)}^{+}+e^{-}\right) \rightarrow * \mathrm{O}+\mathrm{H}_{2} \mathrm{O}_{(a q)}+2\left(\mathrm{H}_{(a q)}^{+}+e^{-}\right) \\
& * \mathrm{O}+\mathrm{H}_{2} \mathrm{O}_{(a q)}+2\left(\mathrm{H}_{(a q)}^{+}+e^{-}\right) \rightarrow * \mathrm{OH}+\mathrm{H}_{2} \mathrm{O}_{(a q)}+\mathrm{H}_{(a q)}^{+}+e^{-} \\
& * \mathrm{OH}+\mathrm{H}_{2} \mathrm{O}_{(a q)}+\mathrm{H}_{(a q)}^{+}+e^{-} \rightarrow *+2 \mathrm{H}_{2} \mathrm{O}_{(a q)}
\end{aligned}
$$

This is clearly identified from the metadynamics simulation of the SW-N3N3' system as discussed below, where the $\mathrm{H}_{2} \mathrm{O}_{2}$ hydrogen peroxide is decomposed into an *O intermediate and one $\mathrm{H}_{2} \mathrm{O}$ molecule in the first step. The second step is the conversion of the ${ }^{*} \mathrm{O}$ intermediate into an $* \mathrm{OH}$ intermediate. The final third step is the removal of the $* \mathrm{OH}$ intermediate from the $\mathrm{CMC}$ surface. The corresponding free energy variations for the second and third steps are $\Delta \mathrm{G}{ }^{*}{ }_{\mathrm{OH}}-\Delta \mathrm{G} *_{\mathrm{O}}$ and $-\Delta \mathrm{G} *_{\mathrm{OH}}$, respectively. The linear relationship for ${ }^{*} \mathrm{O}$ and $* \mathrm{OH}$ is " $\Delta \mathrm{G} *_{\mathrm{O}}=2 \Delta \mathrm{G} *_{\mathrm{OH}}+0.3$ " as discussed in our former work. ${ }^{9}$ In this case, the maximum limiting potential turns out to be 1.62 $\mathrm{V}$, corresponding to $\Delta \mathrm{G}{ }^{*} \mathrm{OH}=1.62 \mathrm{eV}$. Actually, the value of $\Delta \mathrm{G}{ }^{*} \mathrm{OH}$ falls usually in the range $0.2 \sim 1.3 \mathrm{eV}$, and the formation free energy of $\Delta \mathrm{G} *_{\mathrm{OH}}$ can barely approach $1.62 \mathrm{eV} .{ }^{9}$ Qualitatively speaking, the decrease in free energy of the third step is smaller than that of the second step. Therefore, the limiting potential is determined by the removal of the ${ }^{*} \mathrm{OH}$ intermediate. Further details about all the three reaction pathways are provided in the Supporting Information. 
The corresponding limiting potentials are mainly determined by the bond strength of the ${ }^{*} \mathrm{OH}$ intermediate formed on the CMCs surface. To make this statement more quantitative, we computed the formation free energy of the ${ }^{*} \mathrm{OH}$ intermediate; the results are presented in Figure 2(b) for all the structures considered in this work. The formation energies $(\Delta \mathrm{G} * \mathrm{OH})$ for the G-N, G-NN ${ }^{\mathrm{AB}}$, SW-N1, SW-N2, SW-N3 and SW-N3N3' systems are calculated according to our proposed procedure ${ }^{9}$ and all values are in the range $0.2-1.3 \mathrm{eV}$, as shown in Figure 2(b).

The kinetics for $\mathrm{H}_{2} \mathrm{O}_{2}$ reduction are extracted from the free energy landscape provided by the metadynamics simulations. Specifically, the two CVs used to inspect the reaction pathway are the coordination number between the two $\mathrm{O}$ atoms in $\mathrm{H}_{2} \mathrm{O}_{2}(\mathrm{CV} 1)$ and the distance between one of these $\mathrm{O}$ atoms and the approaching $\mathrm{C}$ site on the CMCs surface (CV2). The specific $\mathrm{C}$ sites selected here is based on our extensive investigations done in former works dedicated exactly to the identification of the possible active sites. ${ }^{9,33-34,41-43}$ More precisely, the $\mathrm{C}$ sites selected here are the ones showing the highest density of states (DOS) just below the Fermi level, thus allowing for electron donation, and the strongest binding energies for the intermediates as shown in Figure 2. On these grounds, we focus here on reaction pathways for $\mathrm{H}_{2} \mathrm{O}_{2}$ reduction realized by these $\mathrm{C}$ sites and we select our collective variables accordingly. The free energy landscapes and related barriers obtained within this approach for the G-N and SW-N3N3' systems are shown in Figure 6 (a) and (b), respectively. The configurations of the initial and final states of the $\mathrm{H}_{2} \mathrm{O}_{2}$ reduction process are shown in Figure $\mathbf{S 1}$ of the Supporting Information, while the evolution of the CVs along the metadynamics trajectory are reported in Figure $\mathbf{S 3}$ for the SWN3N3' structure as an illustrative example. Although we mainly focus on metal free CMCs, the free energy profile for a $\mathrm{FeN}_{4}$ center was also studied since Fe containing CMCs represent one of the most common systems used worldwide and are believed to be better performing than metal- 
free CMCs for ORR in acidic solution. Yet, Fe containing CMCs usually suffer from durability issues due to the formation of radicals during the ORR process as mentioned above. ${ }^{14}$ Here we take iron porphine chloride $(\mathrm{FePCl})$ as an example as the $\mathrm{FeN}_{4} \mathrm{Cl}$ center is a typical ORR active center. $^{44}$

For the G-N structure, the $\mathrm{H}_{2} \mathrm{O}_{2}$ moiety undergoes dissociation into two $\mathrm{OH}$ groups in water solution upon overcoming an activation barrier of $0.90 \mathrm{eV}$. Such a barrier is rather high, thus making very unlikely the hydrogen peroxide reduction via this reaction pathway. For this reason the G-N structure will not be considered in the ongoing discussion. However, for the $\mathrm{FePCl}$ center the calculated barrier is rather modest and amounts to just $0.31 \mathrm{eV}$ as shown in Figure S4, which confirms, indeed, the better performance of this system for $\mathrm{H}_{2} \mathrm{O}_{2}$ dissociation. As shown in Figure S1, the $\mathrm{H}_{2} \mathrm{O}_{2}$ hydrogen peroxide decomposes into an $* \mathrm{OH}$ intermediate and an $\mathrm{OH}$ group. The $\mathrm{OH}$ group can be an $\mathrm{OH}^{-}$anion or a radical $\mathrm{OH}$, which corresponds obviously either to the $\mathrm{OH}^{-}$ion or the $\mathrm{OH}$ radical mechanism. The $\mathrm{OH}$ radical can be realized with a low kinetic barrier on the $\mathrm{FePCl}$ center in comparison with a metal free case when the limiting potential is lower than $0.82 \mathrm{~V}$ as indicated above, but this process would destabilize and eventually destroy the catalytic system. The barrier for $\mathrm{H}_{2} \mathrm{O}_{2}$ dissociation in the absence of any catalyst was probed by BME simulations both in the gas phase and in aqueous solution. Results are summarized in Figure S5 of the Supporting Information. The resulting free energy barrier for the cleavage of the $\mathrm{HO}-\mathrm{OH}$ bond in aqueous solution is $1.89 \mathrm{eV}$, in good agreement with former results $(1.90$ eV). ${ }^{45}$ As expected, the analogous free energy barrier in gas phase is larger and amounts to 2.19 $\mathrm{eV}$. These values are significantly higher than the cases in which CMCs exert their catalytic role, corroborating the importance of CMCs for $\mathrm{H}_{2} \mathrm{O}_{2}$ reduction. 
In the case of the SW-N3N3' system, the metadynamics simulations indicated that $\mathrm{H}_{2} \mathrm{O}_{2}$ can bind to the catalytic surface to form an ${ }^{*} \mathrm{O}$ intermediate adduct, accompanied by the release of one $\mathrm{H}_{2} \mathrm{O}$ molecule in solution (see Figure S1). This promotes the $\mathrm{H}_{2} \mathrm{O}$ mechanism discussed above. The corresponding $\mathrm{H}_{2} \mathrm{O}_{2}$ dissociation barrier is $0.62 \mathrm{eV}$. Here, we summarize that the $\mathrm{OH}$ radical can only be generated with a low kinetic barrier on metal doped $\mathrm{CMCs}$ such as the FePCl center $(0.31 \mathrm{eV})$. For metal free CMCs, the more favorable kinetic pathway is to form an $* \mathrm{O}$ and $\mathrm{H}_{2} \mathrm{O}$, analogous to that for SW-N3N3' system $(0.62 \mathrm{eV})$. This may explain the long durability of metal free CMCs, while Fe containing CMCs are easily destroyed by radicals.

As the limiting steps for the two-electron $\mathrm{H}_{2} \mathrm{O}_{2}$ reduction are mainly determined by the removal of the ${ }^{*} \mathrm{OH}$ intermediate adduct bound to the CMCs surface, the volcano plot for the $\mathrm{H}_{2} \mathrm{O}_{2}$ reduction of Figure 3 (b) is based on the use of the quantity $\Delta \mathrm{G} * \mathrm{OH}$ as a descriptor. Here we set the maximum limiting potential to $1.36 \mathrm{~V}$ according to the second reaction pathway. This choice is based on our finding that the $\Delta \mathrm{G} * \mathrm{OH}$ is mainly in the range of $0.2 \mathrm{eV} \sim 1.3 \mathrm{eV}$. As shown in Figure 3 (b), the G-N and G-NN ${ }^{\mathrm{AB}}$ systems can approach the maximum limiting potential, but the doped perfect graphene structures show evident difficulties in promoting the dissociation of the $\mathrm{H}_{2} \mathrm{O}_{2}$ molecule during the first steps, as all metadynamics simulations evidenced. For the SW-N1, SW-N2, and SW-N3 structures, the $\mathrm{H}_{2} \mathrm{O}_{2}$ reduction limiting potentials are relatively low, namely around or lower than $0.5 \mathrm{~V}$. Interestingly, the SW-N3N3' structure shows both a relatively high limiting potential $(1.06 \mathrm{~V})$ and an energetically affordable $\mathrm{H}_{2} \mathrm{O}_{2}$ dissociation barrier of $0.62 \mathrm{eV}$. The SW-N3N3' structure is also the most stable among all possible two nitrogen doped Stone-Wales defect, as found in former works. ${ }^{9,46}$ We remark that the volcano plot shown in Figure 3 for indirect ORR refers specifically to the reaction in acidic solutions. 
This is substantially different from the direct ORR occurring in alkaline solution previously reported. ${ }^{47}$

\subsection{Different pathways for direct and indirect ORR.}

So far, we have clarified the mechanisms and identified the active sites for the formation and reduction of $\mathrm{H}_{2} \mathrm{O}_{2}$ on CMCs in acidic solutions. On these grounds, we can conclude that three different routes are viable reaction pathways for ORR on CMCs in acidic solutions. This is already an indication for suppressing $2 \mathrm{e}^{-} \mathrm{ORR}$, avoiding $\mathrm{OH}$ production on $\mathrm{CMCs}$ and promoting the direct four electrons ORR. In the first one, if the $\mathrm{H}$ abstraction barrier is much higher than that for $\mathrm{O}_{2}$ adsorption, only a direct four-electron $\mathrm{ORR}$ can occur via the $\mathrm{O}_{2}$ adsorption mechanism. In this case, the half-wave potential can be as high as $0.8 \mathrm{~V}$ as previously discussed. ${ }^{9}$ In the second route the $\mathrm{H}$ abstraction barrier is comparable to that for $\mathrm{O}_{2}$ adsorption. Thus, if the $\mathrm{H}_{2} \mathrm{O}_{2}$ reduction barrier is much higher than that for $\mathrm{O}_{2}$ adsorption / $\mathrm{H}$ abstraction, both direct four-electron via $\mathrm{O}_{2}$ adsorption and two-electron ORR processes via $\mathrm{H}$ abstraction can be realized. Then, the overall ETN is expected to range between 2 and 4 and the linear sweep voltammograms (LSV) curve should be different with respect to the pure direct four-electron ORR. On the other hand, if the $\mathrm{H}_{2} \mathrm{O}_{2}$ reduction barrier is considerably lower than that for $\mathrm{O}_{2}$ adsorption / $\mathrm{H}$ abstraction, both direct and indirect four-electron ORR can occur. If this is the case, the ETN should also amount to about 4. In the third viable route, the $\mathrm{H}$ abstraction barrier can be much lower than that for $\mathrm{O}_{2}$ adsorption. When this happens, if the $\mathrm{H}_{2} \mathrm{O}_{2}$ reduction barrier is high, then only a two electron process can occur. The half-wave potential is then about $0.4 \mathrm{~V}$ and the ETN is 2. If the $\mathrm{H}_{2} \mathrm{O}_{2}$ reduction barrier is also low, an indirect four-electron ORR can be realized. This would be indicated by a low half-wave potential and a value of the ETN equal to 4 . All the direct and indirect ORR pathways discussed here are summarized in Figure 7. Finally, 
we call the attention on the fact that the formation of the $\mathrm{H}_{2} \mathrm{O}_{2}$ hydrogen peroxide is determined by the $\mathrm{H}$ abstraction, while the $\mathrm{H}_{2} \mathrm{O}_{2}$ reduction is determined by the removal of *OH.

As metal free CMCs usually have high $\mathrm{O}_{2}$ adsorption barriers, the ORR better performance would correspond to the third route. However, it would suffer from a low half-wave potential whether the ETN is 2 or 4 as discussed above. Thus, for metal free systems the ORR in acidic solutions is characteristic by a low half-wave potential $(\sim 0.4 \mathrm{~V})$, in full agreement with experiments. For non-noble metal doped $\mathrm{CMCs}$, such as Fe containing CMCs for instance, the first and second cases should be the dominating pathways because the $\mathrm{O}_{2}$ adsorption barriers are generally low for metal doped CMCs. However, in this case, the drawback is the generation of $\mathrm{OH}$ radicals, discussed in the $\mathrm{OH}$ radical mechanism for $\mathrm{H}_{2} \mathrm{O}_{2}$ reduction, eventually resulting in a destabilization of the catalytic system. We can remark also that the $\mathrm{H}_{2} \mathrm{O}_{2}$ can be produced via both an adsorption and $\mathrm{H}$ abstraction mechanism. Fortunately, the critical half-wave potential for $\mathrm{OH}$ radical generation is rather high $(0.82 \mathrm{~V})$. Note also that the maximum half-wave potential obtained in experiments is also around $0.8 \mathrm{~V}$ (the onset potential is generally about $0.1-0.2 \mathrm{~V}$ higher than half-wave potential). So, a high efficiency CMCs catalyst for ORR in acidic solution should 1) show strong binding to $H$ or hindering bind to $H$ to suppress the $H$ abstraction mechanism; 2) show low activation barriers for $\mathrm{O}_{2}$ adsorption to improve the direct four-electron ORR; 3) be characterized by a half-wave potential lower than $0.82 \mathrm{~V}$ to avoid generation of $\mathrm{OH}$ radicals. This provides a roadmap and potentially a new strategy for developing CMCs in acidic solutions.

\section{Conclusions}


By combining first principles molecular dynamics, enhanced with free energy sampling techniques, and static DFT simulations, we clarified the detailed mechanisms and identified the active sites responsible for the indirect four-electron ORR and related two-electron ORR on CMCs in acidic solution. The indirect four-electron ORR is a combination of a first two-electron ORR resulting in the formation of $\mathrm{H}_{2} \mathrm{O}_{2}$ and a second one responsible for the $\mathrm{H}_{2} \mathrm{O}_{2}$ reduction. Upon careful identification of the active sites for $\mathrm{H}_{2} \mathrm{O}_{2}$ formation on the CMCs surfaces via $\mathrm{H}$ abstraction, we provide an atomic-level insight and explain the origin of the low half-wave potential (around $0.4 \mathrm{~V}$ ) for two-electron ORR. We find that the SW-N3 structure is a favorable system for $\mathrm{H}_{2} \mathrm{O}_{2}$ formation via an $\mathrm{H}$ abstraction mechanism. We also identify three different reaction mechanisms for the $\mathrm{H}_{2} \mathrm{O}_{2}$ reduction on CMCs, specifically (i) a mechanism involving the formation of $\mathrm{OH}^{-}$, (ii) a second one passing across the formation of an $\mathrm{OH}$ radical and a (iii) third one resulting in the production of $\mathrm{H}_{2} \mathrm{O}$. For all these mechanisms, the rate determining step for $\mathrm{H}_{2} \mathrm{O}_{2}$ reduction is the removal of an ${ }^{*} \mathrm{OH}$ intermediate generally anchored to the $\mathrm{CMC}$ surface. The SW-N3N3' structure is remarkably favorable for $\mathrm{H}_{2} \mathrm{O}_{2}$ reduction via the $\mathrm{H}_{2} \mathrm{O}$ production mechanism with a limiting potential of $1.06 \mathrm{~V}$. The $\mathrm{FePCl}$ center is favorable to the $\mathrm{OH}$ radical mechanism, and the critical potential for $\mathrm{OH}$ radical generation is $0.82 \mathrm{~V}$. The $\mathrm{OH}$ radical is kinetically much easier to generate on Fe containing structures than that for the $\mathrm{N}$ doped cases. Being this a parasite process in terms of the stability of a catalytic system, this may explain why $\mathrm{Fe}$ containing catalysts are easily destroyed and pathologically affected by durability issues, as opposed to the stability displayed by metal free CMCs upon ORR processes. The whole indirect four-electron processes have been summarized and directly related to the half-wave potential and ETN experimentally measurable. The results indicate that the performance of ORR in acidic solutions can be improved by suppressing undesired $2 \mathrm{e}^{-} \mathrm{H}_{2} \mathrm{O}_{2}$ 
formation via $\mathrm{H}$ abstraction mechanism, avoiding $\mathrm{OH}$ production via $\mathrm{OH}$ radical mechanism during $\mathrm{H}_{2} \mathrm{O}_{2}$ reduction, and promoting direct $4 \mathrm{e}^{-} \mathrm{ORR}$ by decreasing $\mathrm{O}_{2}$ adsorption battier. This not only disclose a new way to improve and design high efficient CMCs for ORR in acid solutions but also provides a guideline for future development of ORR catalysts for practical applications in acidic environments.

\section{ASSOCIATED CONTENT}

Supporting Information. Limiting potential calculations; Mechanisms for $\mathrm{H}_{2} \mathrm{O}_{2}$ formation and reduction; Proton transfer barrier for SW-N3 structure and collective variables variation for SW-N3N3' structure; $\mathrm{H}_{2} \mathrm{O}_{2}$ reduction on $\mathrm{FePCl}$ center; $\mathrm{H}_{2} \mathrm{O}_{2}$ dissociation in vacuum and pure water.

\section{AUTHOR INFORMATION}

\section{Corresponding Author}

*Correspondence and requests for materials should be addressed to Guo-Liang Chai (* E-mail: g.chai@fjirsm.ac.cn).

\section{ACKNOWLEDGMENT}

This work is supported by the National Natural Science Foundation of China (grant no. 21703248) and the National Basic Research Program of China (grant no. 2014CB845605). The authors would also acknowledge the use of the computing facility and corresponding associated support services at Fujian Institute of Research on the Structure of Matter and the supercomputing facilities (Cray XC30 and Fujitsu CX250 Cluster) at Japan Advanced Institute 
of Science and Technology (JAIST). M.B. thanks Pôle HPC - Equipex Equip@Meso, University of Strasbourg, GENCI under allocation DARI-A2 A0020906092 and the LaBex "Nanoparticles Interacting with their Environment" ANR-11-LABX-0058_NIE.

\section{ABBREVIATIONS}

Oxygen reduction reaction (ORR); Carbon materials catalysts (CMCs).

\section{REFERENCES}

(1) Lefevre, M.; Proietti, E.; Jaouen, F.; Dodelet, J. P. Science 2009, 324, 71-74.

(2) Wu, G.; More, K. L.; Johnston, C. M.; Zelenay, P. Science 2011, 332, 443-447.

(3) Xia, B. Y.; Yan, Y.; Li, N.; Wu, H. B.; Lou, X. W.; Wang, X. Nat. Energy 2016, 1, 15006.

(4) Zitolo, A.; Goellner, V.; Armel, V.; Sougrati, M. T.; Mineva, T.; Stievano, L.; Fonda, E.; Jaouen, F. Nat. Mater. 2015, 14, 937-942.

(5) Suntivich, J.; Gasteiger, H. A.; Yabuuchi, N.; Nakanishi, H.; Goodenough, J. B.; ShaoHorn, Y. Nat. Chem. 2011, 3, 546-550.

(6) Holewinski, A.; Idrobo, J. C.; Linic, S. Nat. Chem. 2014, 6, 828-834.

(7) Steele, B. C. H.; Heinzel, A. Nature 2001, 414, 345.

(8) Gong, K. P.; Du, F.; Xia, Z. H.; Durstock, M.; Dai, L. M. Science 2009, 323, 760

(9) Chai, G. L.; Hou, Z. F.; Shu, D. J.; Ikeda, T.; Terakura, K. J. Am. Chem. Soc. 2014, 136, 13629.

(10) Liu, X.; Dai, L. Nat. Rev. Mater. 2016, 1, 16064. 
(11) Fellinger, T. P.; Hasché, F.; Strasser, P.; Antonietti, M. J. Am. Chem. Soc. 2012, 134, 4072-4075.

(12) Park, J.; Nabae, Y.; Hayakawa, T.; Kakimoto, M. ACS Catalysis 2014, 4, 3749-3754.

(13) Liu, Y.; Quan, X.; Fan, X.; Wang, H.; Chen, S. Angew. Chem. Int. Ed. 2015, 54, 6837.

(14) Burkitt, R.; Whiffen, T. R.; Yu, E. H. Applied Catalysis B: Environmental 2016, 181, 279288.

(15) Muthukrishnan, A.; Nabae, Y.; Okajima, T.; Ohsaka, T. ACS Catal. 2015, 5, 5194-5202.

(16) Chai, G.; Hou, Z.; Ikeda, T.; Terakura, K. J. Phys. Chem. C 2017, 121, 14524-14533.

(17) Car R.; Parrinello, M. Phys. Rev. Lett. 1985, 55, 2471.

(18) CPMD. MPI fur Festkorperforshung Stuttgart, 1997-2001. IBM Corp, 1990-2015 http://www.cpmd.org (1990-2017).

(19) Kohn, W.; Sham, L.J., Phys. Rev. 1965, 140, A1133-A1138.

(20) Sprik M.; Ciccotti, G. J. Chem. Phys. 1998, 109, 7737.

(21) Hamprecht, F. A.; Cohen, A. J.; Tozer, D. J.; Handy, N. C. J. Chem. Phys. 1998, 109, 6264.

(22) Troullier, N.; Martins, J. L. Phys. Rev. B 1991, 43, 1993.

(23) Sprik, M.; Hutter, J.; Parrinello, M. J. Chem. Phys. 1996, 105, 1142.

(24) Laio, A.; Parrinello, M. Proc. Natl. Acad. Sci. 2002, 99, 12562-12566. 
(25) Barducci, A.; Bonomi, M.; Parrinello, M Wiley Interdisciplinary Reviews - Comput. Mol. Sci. $2011,1,826-843$.

(26) Iannuzzi, M.; Laio, A.; Parrinello, M. Phys. Rev. Lett. 2003, 90, 238302.

(27) Giannozzi, P. et al., J. Phys.: Condens. Matter. 2009, 21, 395502.

(28) Perdew, J. P.; Burke K.; Ernzerhof, M. Phys. Rev. Lett. 1996, 77, 3865.

(29) Siahrostami, S.; Verdaguer Casadevall, A.; Karamad, M.; Deiana, D.; Malacrida, P.; Wickman, B.; Escudero Escribano, M.; Paoli, E. A.; Frydendal, R.; Hansen, T. W.; Chorkendorff, I.; Stephens, I. E. L.; Rossmeisl, J. Nat. Mater. 2013, 12, 1137-1143.

(30) Verdaguer Casadevall, A.; Deiana, D.; Karamad, M.; Siahrostami, S.; Malacrida, P.; Hansen, T. W.; Rossmeisl, J.; Chorkendorff, I.; Stephens, I. E. L. Nano Lett. 2014, 14, 16031608.

(31) Koizumi, K.; Boero, M.; Nobusada, K. Chem. Eur. J. 2016, 22, 5181-5188.

(32) Ikeda, T.; Hou, Z.; Chai, G. L.; Terakura, K. J. Phys. Chem. C 2014, 118, 17616-17625.

(33) Wang, X.; Hou, Z.; Ikeda, T.; Huang, S. F.; Terakura, K.; Boero, M.; Oshima, M.; Kakimoto, M.; Miyata, S. Phys. Rev. B 2011, 84, 245434.

(34) Huang, S. F.; Terakura, K.; Ozaki, T.; Ikeda, T.; Boero, M.; Oshima, M.; Ozaki, J.; Miyata, S. Phys. Rev. B 2009, 80, 235410.

(35) Moore, J. W.; Stanitsuki, C. L.; Jurs, P. C. Chemistry: The Molecular Science, $4^{\text {th }}$ ed.; Brooks/Cole: Singapore, 2011, Appendix J. 
(36) Stanbury, D. M. Adv. Inorg. Chem. 1989, 33, 69.

(37) Nørskov, J. K.; Rossmeisl, J.; Logadottir, A.; Lindqvist, L.; Kitchin, J. R.; Bligaard, T.; Jónsson, H. J. Phys. Chem. B 2004, 108, 17886.

(38) Fellinger, T. P.; Hasché, F.; Strasser, P.; Antonietti, M. J. Am. Chem. Soc. 2012, 134, 4072-19 4075.

(39) Park, J.; Nabae, Y.; Hayakawa, T.; Kakimoto, M. ACS Catal. 2014, 4, 3749-3754.

(40) Liu, Y.; Quan, X.; Fan, X.; Wang, H.; Chen, S. Angew. Chem. Int. Ed. 2015, 54, 68376841.

(41) Ikeda, K.; Boero, M.; Huang, S. F.; Terakura, K.; Oshima, M.; Ozaki, J. J. Phys. Chem. C 2008, 112, 14706-14709.

(42) Ikeda, T.; Boero, M.; Huang, S. F.; Terakura, K.; Oshima, M.; Ozaki, J.; Miyata, S. J. Phys. Chem. C 2010, 114, 8933-8937.

(43) Hou, Z.; Wang, X.; Ikeda, T.; Huang, S. F.; Terakura, K.; Boero, M.; Oshima, M.; Kakimoto, M.; Miyata, S. J. Phys. Chem. C 2011, 115, 5392-5403.

(44) Wasylenko, D. J.; Rodríguez, C.; Pegis, M. L.; Mayer, J. M. J. Am. Chem. Soc. 2014, 136, $12544-12547$.

(45) Bach, R. D.; Ayala, P. Y.; Schlegel, H. B. J. Am. Chem. Soc. 1996, 118, 12758-12765.

(46) Hou, Z.; Wang, X.; Ikeda, T.; Terakura, K.; Oshima, M.; Kakimoto, M.; Miyata, S. Phys. Rev. B 2012, 85, 165439. 
(47) To, J. W. F.; Ng, J. W. D.; Siahrostami, S.; Koh, A. L.; Lee, Y.; Chen, Z.; Fong, K. D.; Chen, S.; He, J.; Bae, W. G.; Wilcox, J.; Jeong, H. Y.; Kim, K.; Studt, F.; Nørskov, J. K. Jaramillo, T. F.; Bao, Z. Nano Research 2017, 10, 1163. 


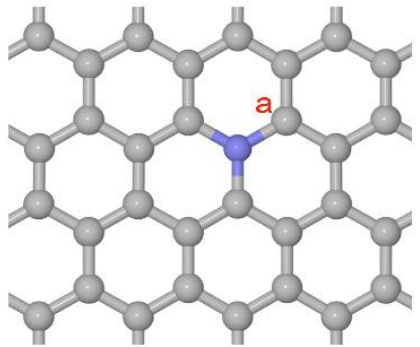

(a)

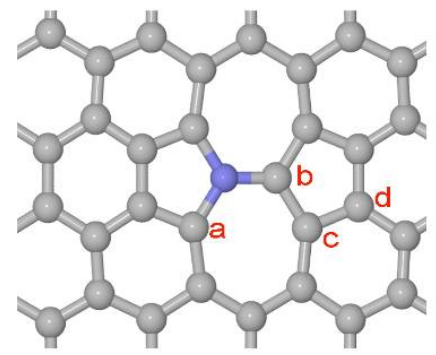

(c)

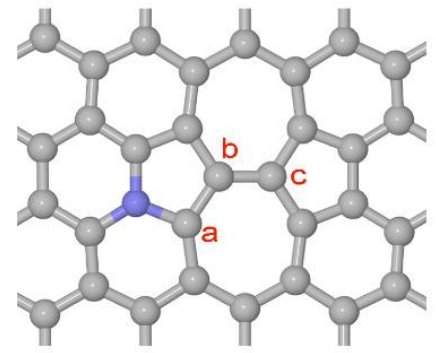

(e)

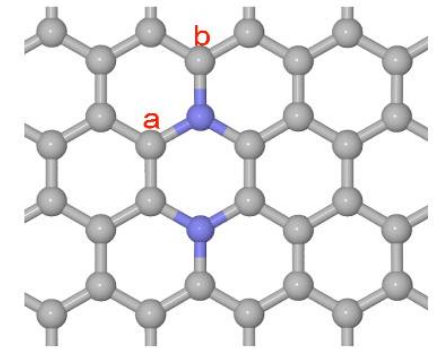

(b)

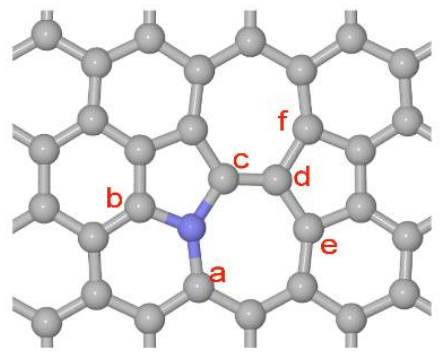

(d)

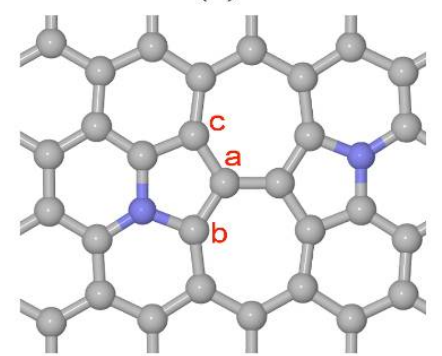

(f)

Figure 1. Atomic structures of (a) G-N, (b) G-NN ${ }^{\mathrm{AB}}$, (c) SW-N1, (d) SW-N2, (e) SW-N3 and (d) SW-N3N3' considered in the present work for the ORR processes. Grey and blue balls indicate $\mathrm{C}$ and $\mathrm{N}$ atoms, respectively. 

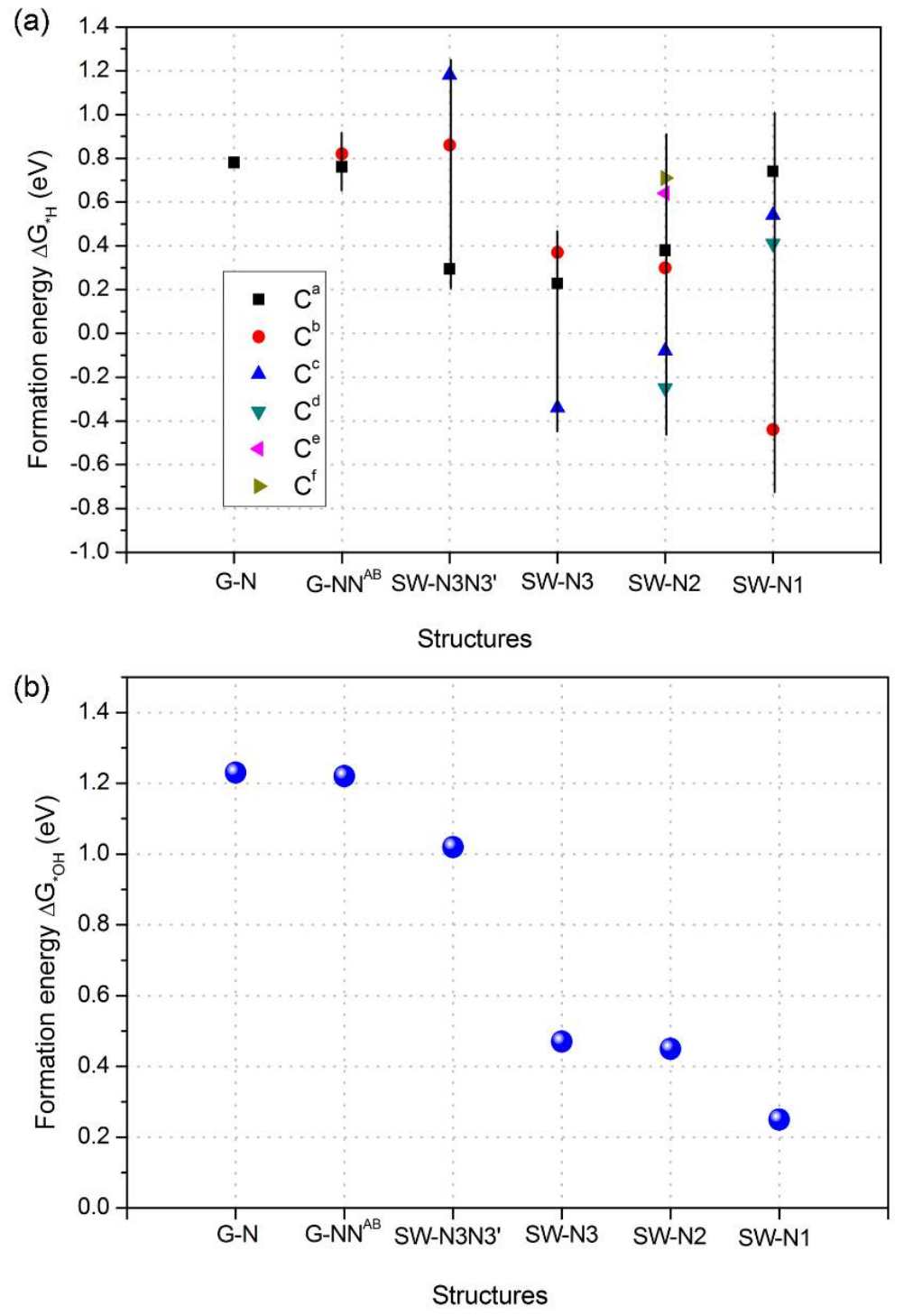

Figure 2. Formation energies of (a) $* \mathrm{H}$ and (b) $* \mathrm{OH}$ for G-N, G-NN ${ }^{\mathrm{AB}}, \mathrm{SW}-\mathrm{N} 1, \mathrm{SW}-\mathrm{N} 2, \mathrm{SW}-$ N3 and SW-N3N3' structures. The asterisk '*' denotes a specific site on carbon materials catalysts as shown in Figure 1. 

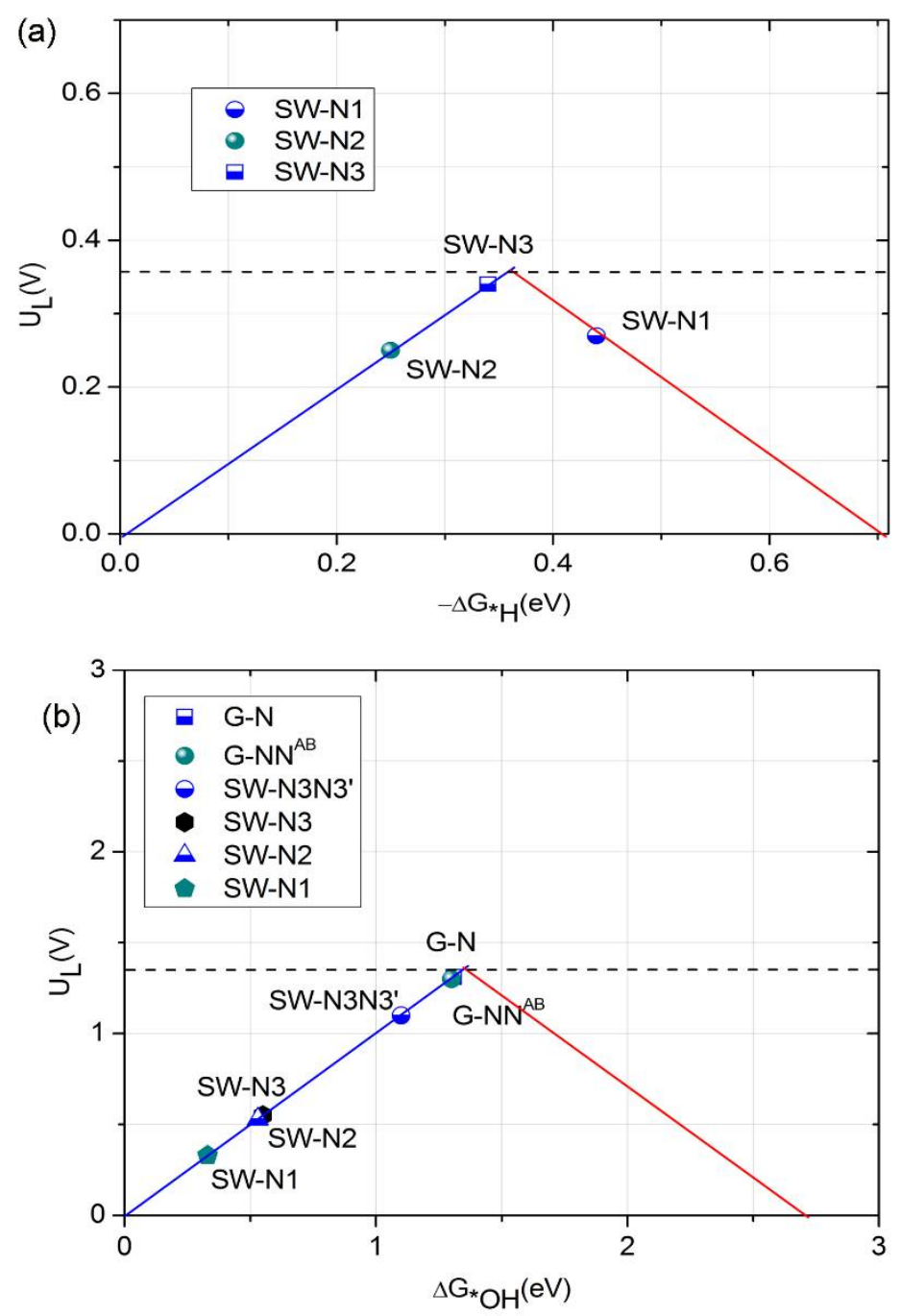

Figure 3. Volcano plot for (a) $\mathrm{H}_{2} \mathrm{O}_{2}$ formation on SW-N1, SW-N2, and SW-N3 structures, and (b) $\mathrm{H}_{2} \mathrm{O}_{2}$ reduction on G-N, G-NN ${ }^{\mathrm{AB}}$, SW-N1, SW-N2, SW-N3 and SW-N3N3' structures. 


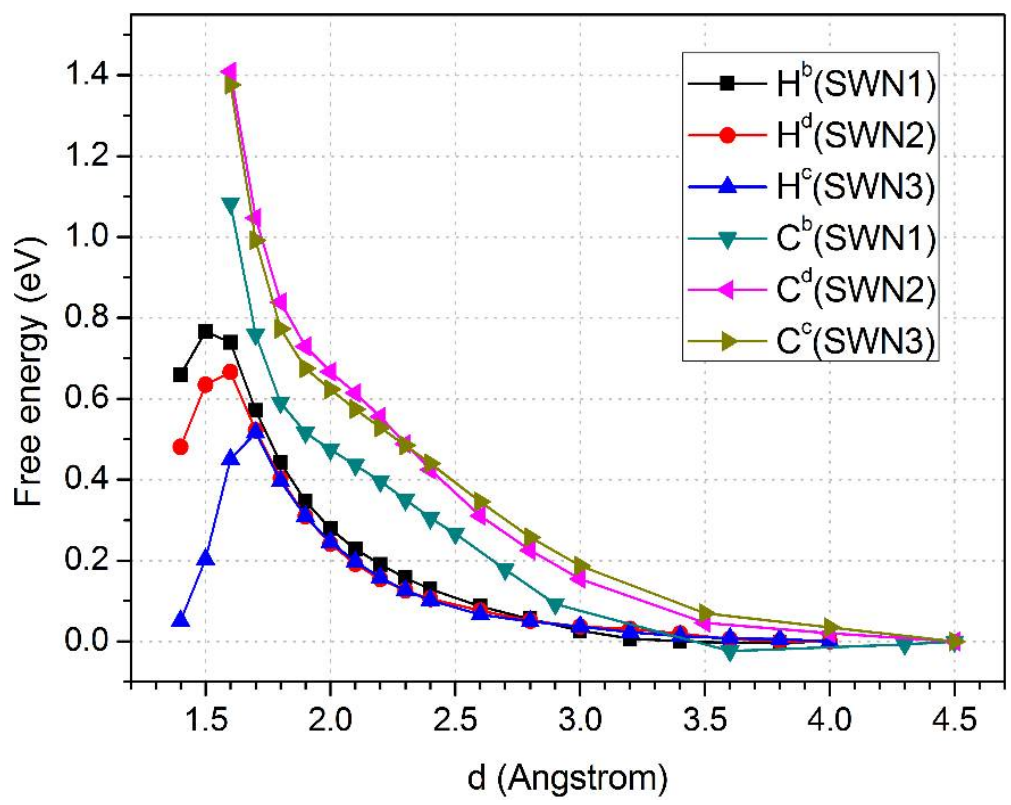

Figure 4. $\mathrm{H}$ abstraction and $\mathrm{O}_{2}$ adsorption free energy profiles for the SW-N1, SW-N2, and SWN3 structures. The $\mathrm{O}_{2}$ adsorption free energy profiles reported in this figure refer to the results presented in Ref. 9. Symbols refer to the sampled points, while lines are intended as a guideline to the eye. 


$$
\begin{aligned}
& *+\mathrm{H}_{2} \mathrm{O}_{2}+2 \mathrm{H}^{+}+2 \mathrm{e}^{-} \text {Maximum half wave potential: } 1.36 \mathrm{~V} \\
& -3.54+0.83+\Delta \mathrm{G}_{* \mathrm{OH}} * \mathrm{OH}+\mathrm{OH}^{-}+2 \mathrm{H}^{+}+\mathrm{e}^{-} \\
& -0.83 \mathrm{eV} * \mathrm{OH}+\mathrm{H}_{2} \mathrm{O}+\mathrm{H}^{+}+\mathrm{e}^{-} \\
& -\Delta \mathrm{G}_{* \mathrm{OH}} \cdots+2 \mathrm{H}_{2} \mathrm{O} \\
& *+\mathrm{H}_{2} \mathrm{O}_{2}+2 \mathrm{H}^{+}+2 \mathrm{e}^{-} \\
& \text {Maximum half wave potential: } 0.82 \mathrm{~V} \\
& -3.54+\Delta \mathrm{G}_{* \mathrm{OH}}+2.72 * \mathrm{OH}+\mathrm{OH}+2 \mathrm{H}^{+}+2 \mathrm{e}^{-} \\
& -\Delta \mathrm{G} \mathrm{OH} * \mathrm{OH}+\mathrm{H}_{2} \mathrm{O}+\mathrm{H}^{+}+\mathrm{e}^{-} \\
& -2.72+\Delta \mathrm{G}_{* \mathrm{OH}} * \mathrm{OH}+\mathrm{H}_{2} \mathrm{O}+\mathrm{H}^{+}+\mathrm{e}^{-} \\
& -\Delta \mathrm{G}_{{ }_{\mathrm{OH}}} *+2 \mathrm{H}_{2} \mathrm{O} \\
& *+\mathrm{H}_{2} \mathrm{O}_{2}+2 \mathrm{H}^{+}+2 \mathrm{e}^{-} \\
& \begin{array}{l}
-3.54+\Delta \mathrm{G} * \mathrm{O} * \mathrm{O}+\mathrm{H}_{2} \mathrm{O}+2 \mathrm{H}^{+}+2 \mathrm{e}^{-} \\
\mathrm{H}^{-}
\end{array} \\
& \Delta \mathrm{G}_{* \mathrm{OH}}-\Delta \mathrm{G}_{* \mathrm{O}} * \mathrm{OH}+\mathrm{H}_{2} \mathrm{O}+\mathrm{H}^{+}+\mathrm{e}^{-} \\
& -\Delta \mathrm{G}_{* \mathrm{OH}}{ }^{*}+2 \mathrm{H}_{2} \mathrm{O}
\end{aligned}
$$

Figure 5. $\mathrm{H}_{2} \mathrm{O}_{2}$ reduction pathways for (a) the $\mathrm{OH}^{-}$hydroxyl anion mechanism, (b) the $\mathrm{OH}$ radical mechanism, and (c) the $\mathrm{H}_{2} \mathrm{O}$ mechanism. 

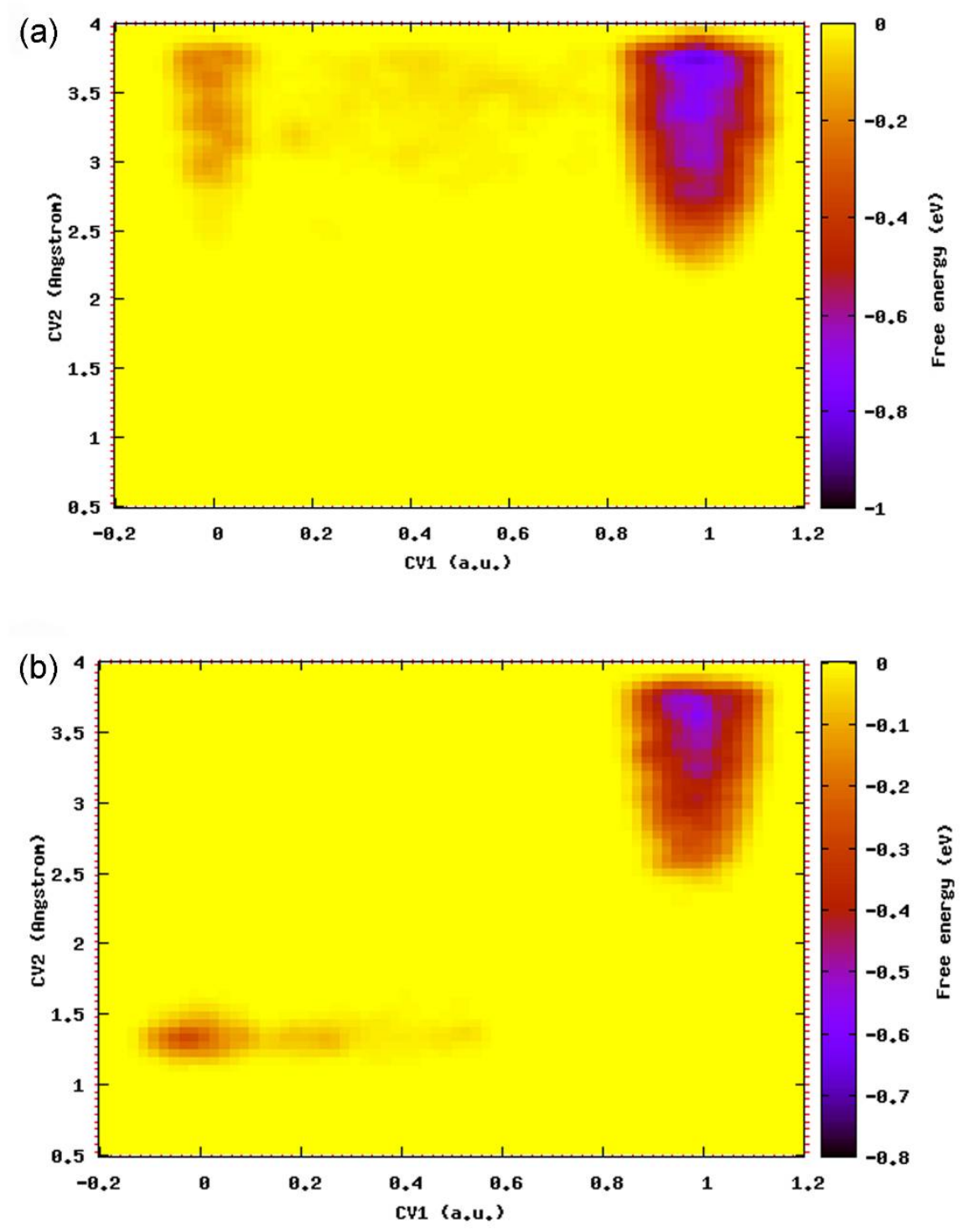

Figure 6. $\mathrm{H}_{2} \mathrm{O}_{2}$ activation free energy landscapes for (a) the $\mathrm{G}-\mathrm{N}$ and (b) $\mathrm{SW}-\mathrm{N} 3 \mathrm{~N} 3$ ' structures. $\mathrm{CV} 1$ is the coordination number between the two $\mathrm{O}$ atoms in $\mathrm{H}_{2} \mathrm{O}_{2}$ molecule, whereas $\mathrm{CV} 2$ is the distance between $\mathrm{O}$ atom in $\mathrm{H}_{2} \mathrm{O}_{2}$ molecule and the $\mathrm{C}^{\text {a }}$ site in $\mathrm{G}-\mathrm{N}$ and $\mathrm{SW}-\mathrm{N} 3 \mathrm{~N} 3$ ' structures as explained in the text. 


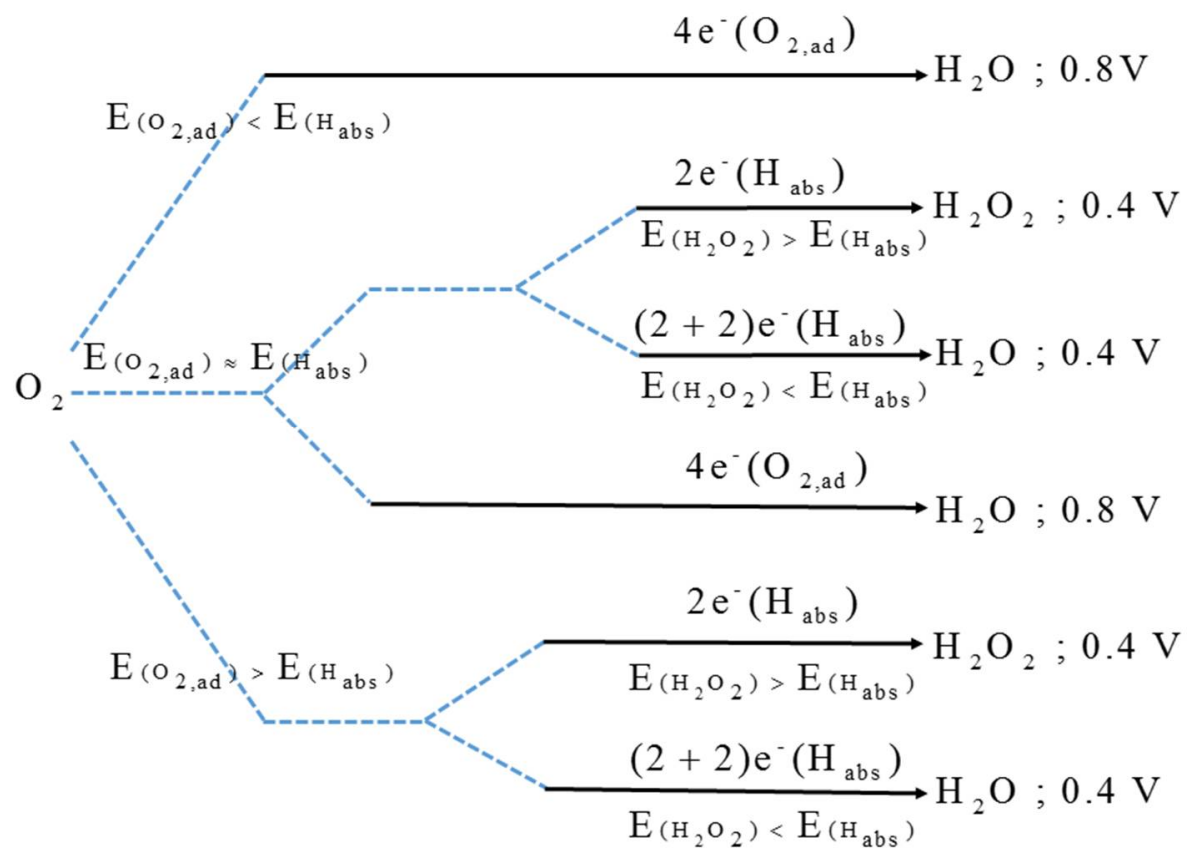

Figure 7. Pathways for direct and indirect $\mathrm{ORR}$ via $\mathrm{O}_{2}$ adsorption mechanisms and hydrogen abstraction mechanisms. $\mathrm{E}\left(\mathrm{O}_{2}, a d\right), \mathrm{E}\left(\mathrm{H}_{\mathrm{abs}}\right)$ and $\mathrm{E}\left(\mathrm{H}_{2} \mathrm{O}_{2}\right)$ denotes for activation barriers for $\mathrm{O}_{2}$ adsorption, hydrogen abstraction and $\mathrm{H}_{2} \mathrm{O}_{2}$ reduction, respectively. 
Table of Contents

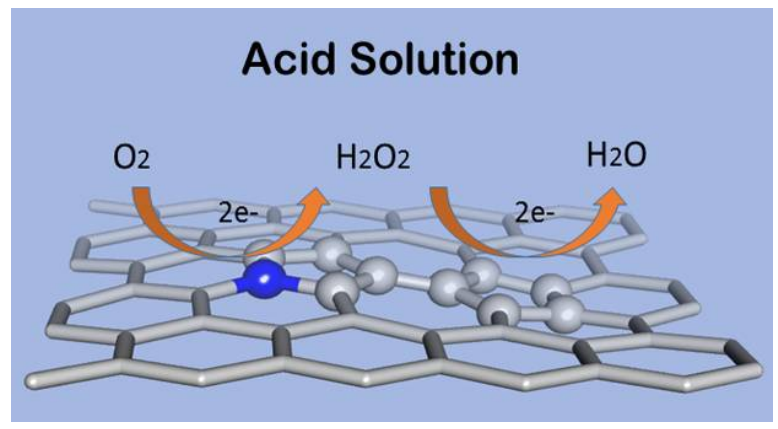

